\title{
Educação Superior no Brasil e a disputa pela concepção de qualidade no Sinaes
}

\author{
Higher education in Brazil and the controversy by the quality concept in Sinaes \\ Educación superior en Brasil y la disputa por el concepto de calidad en Sinaes
}

\author{
MARIA DO CARMO LACERDA PEIXOTO \\ MARIA DAS GRAÇAS MEDEIROS TAVARES \\ IVANILDO RAMOS FERNANDES
}

FABIANE ROBL

\begin{abstract}
Qualidade é conceito polissêmico, conforme concepções e interesses das arenas de poder da Educação Superior. Essas concepções têm assimetrias entre a iniciativa privada e o setor público, podendo mascarar pedagogias de gerenciamento e performatividade. $\mathrm{O}$ artigo aborda a qualidade na avaliação da Educação Superior como conceito em disputa entre a avaliação como um processo de caráter formativo e emancipatório e como um referencial básico da regulação. Essa disputa explicita a polissemia da qualidade na avaliação, ressaltando a perspectiva regulatória presente no sistema educacional brasileiro.
\end{abstract}

Keywords: Educação superior; avaliação; qualidade; arenas de poder; performatividade.

Resumo: Quality is a polysemic concept according to conceptions and interests of power arenas of higher education. These conceptions have asymmetries between the private and the public sector and can mask pedagogies management and performativity. The paper discusses the quality in the evaluation of higher education as a concept in dispute between the evaluation as a formative and emancipatory process and as a basic framework of regulation. This dispute explains the polysemy of quality evaluation, emphasizing the regulatory perspective present in the Brazilian educational system.

Palavras-chave: Higher education; evaluation; quality; power arenas; performativity.

Resumen: Calidad es concepto polisémico, de acuerdo con concepciones e intereses de los ámbitos de poder de la educación superior. Esas concepciones presentan asimetrías entre el sector privado y el sector público, siendo posible enmascarar pedagogías de gestión y performatividad. El estudio aborda la calidad en la evaluación de la educación superior como un concepto en disputa entre la evaluación como un proceso de carácter formativo y emancipador y como referencial básico de la regulación. Esta disputa explicita la polisemía de la calidad en la evaluación, haciendo hincapié en la perspectiva regulatoria presente en el sistema educativo brasileño.

Palabras clave: Educación superior; evaluación; calidad; ámbitos de poder; performatividad. 


\section{INTRODUÇÃO}

Os significados atribuídos ao conceito qualidade na educação superior não são unívocos, derivando sua polissemia das múltiplas percepções que os setores públicos e privados dele têm em termos de diretrizes, finalidades e, consequentemente, qualidade. Essa polissemia tem contribuído para mascarar o que, de fato, os diferentes atores entendem por esse conceito. No presente texto, discutimos algumas das diferentes formas como vem sendo trabalhado o conceito de qualidade na Educação Superior, com o objetivo de aprofundar o debate sobre a questão.

O artigo reflete o acúmulo conceitual alcançado no âmbito da pesquisa Avaliação, Expansão e Qualidade da Educação Superior no Século XXI: Uma Análise sobre o Conceito de Qualidade nos Cursos de Graduação durante o Período Pós-SINAES - 2004/2012, que integra o projeto OBEDUC: Políticas de Expansão da Educação Superior no Brasil, da Rede Universitas/Br. Esse trabalho coletivo reúne profissionais de diferentes instituições brasileiras de ensino superior que também integram o grupo de pesquisa Observatório e Pesquisa das Políticas de Avaliação da Educação Superior (POW1), um espaço para aglutinar reflexões e ações sobre a avaliação na Educação Superior e o conceito de qualidade, ora em discussão.

Na primeira parte do texto, é feita uma discussão acerca de como a qualidade se relaciona com os conceitos de gerencialismo e performatividade presentes na gestão da educação e, na sequência, são abordadas questões relacionadas às implicações trazidas pela Nova Gestão Pública (NGP), caracterizada por uma cultura empresarial altamente competitiva. O novo gerencialismo daí decorrente tem preocupação constante com a qualidade associada a valores próximos aos da empresa privada, que se preocupa com o consumidor, traduzindo qualidade por eficácia e eficiência. Para além da vinculação ao fazer próprio das universidades, o conceito caracteriza a Educação Superior como setor da economia, onde atuam outras arenas de poder.

$\mathrm{Na}$ terceira parte do artigo, caracteriza-se a concepção de qualidade como campo em disputa envolvendo o sistema federal de ensino (SFE), que compreende as instituições de Educação Superior (IES) mantidas pela União e pelo setor privado. Nosso recorte é o Sistema Nacional de Avaliação da Educação Superior (SINAES) e as IES destinatárias dessa política, compreendendo não apenas a disputa que se dá entre os setores público e privado, mas, sobretudo, internamente nas arenas de poder dos órgãos responsáveis pela regulação da qualidade. 


\section{GERENCIALISMO, PERFORMATIVIDADE E QUALIDADE}

No contexto das mudanças políticas e econômicas globais do mundo atual, Dale (2011) observa que as IES estão se movendo num contínuo, passando de produtoras nacionais de capital humano para se tornarem atores-chave com a emergência da economia global do conhecimento. Esse processo se dá em diferentes países e em distintas etapas, havendo uma globalização crescente das bases e dos critérios que medem o seu progresso, que caracteriza uma agenda supranacional para a educação, com o controle de resultados por meio de avaliações em larga escala e o estabelecimento de classificações das instituições educacionais.

O surgimento da Nova Gestão Pública ${ }^{1}$ fez com que essa perspectiva fosse adotada como fundamento para a abordagem da governança e da regulação de atividades universitárias, assim como em relação à qualidade. Até a sua introdução na educação superior,

Os acadêmicos têm sido essencialmente os únicos e definitivos árbitros do que
agora é implicado pelo uso do termo 'qualidade' [presumindo-se que] a competência
acadêmica era necessária e também suficiente para todos os julgamentos sobre o
que agora é coberto por sistemas de gestão da qualidade. (DALE, 2011, p.60).

Esse autor atribui a instituição de sistemas de gestão da qualidade na educação superior à ênfase crescente da necessidade de as universidades contribuírem, por meio de seu ensino e, especialmente, de sua pesquisa para a economia do conhecimento.

Analisando as características dos estados-nação no cenário da globalização, Ball (2004) observa que os estados passaram de provedores a reguladores das políticas públicas, atuando como auditores e avaliando os resultados alcançados pelos mercados internos. Nesse ambiente, os órgãos de gerenciamento central se baseiam em sistemas de monitoramento e produção de informações, instituindo o gerencialismo como novo paradigma de gestão pública.

Segundo Newman e Clarke (2012, p. 361), o gerencialismo é um pragmatismo racional de meio-fim que privilegia a eficiência e a produtividade, e favorece relações transacionais de intercâmbio e contratação. Frequentemente está associado a sistemas rígidos de controle, metas em cascata e monitoramento de desempenho. Na década de 1990, desenvolveu-se o novo gerencialismo, mais centrado nas pessoas e orientado para a qualidade e a excelência.Nele, os

1 Segundo Robertson (2011), a NGP foi desenhada para desacelerar ou reverter o aumento de despesas públicas, removendo do governo atividades que são assumidas pelo setor privado. 
programas de mudança de cultura procuram deixar a força de trabalho livre para inovar e aperfeiçoar os serviços, introduzindo organizações mais centradas no cliente.

Analisando o processo de reforma do Estado inglês do final do século XX, Newman e Clarke afirmam ter estado presente nele tanto o gerencialismo quanto a gerencialização. O primeiro, como ideologia que legitimava direitos ao poder, especialmente ao de gerir, necessários para alcançar maior eficiência na busca de objetivos organizacionais e sociais. Ele se constitui, além disso, numa estrutura calculista que organiza o conhecimento sobre as metas organizacionais e os meios para alcançá-las, estruturado "em torno de um cálculo interno de eficiência (entradas-saídas) e num cálculo externo de posicionamento competitivo em um campo de relações de mercado" (2012, p. 359).O gerencialismo compreende, ainda, uma série de discursos superpostos, articulando proposições diferentes e até conflitantes, sobre como gerir e o quê deve ser gerido. Já a gerencialização é um "processo de estabelecimento de autoridade gerencial sobre recursos corporativos (materiais, humanos ou simbólicos) e de tomada de decisão corporativa" (Ibidem), sendo, também, um processo de estabelecimento de estruturas calculistas de gerencialismo, as quais definem os termos e condições da tomada de decisão. Seu objetivo é incorporar essas estruturas como as formas de conhecimento que governam padrões de relacionamentos internos e externos, criando formas de gerir e tipos de gestores.

De acordo com Ball, o novo gerencialismo tornou-se, o mecanismo central da reforma política e da reengenharia cultural do setor público nos últimos anos. É o principal meio "pelo qual a estrutura e a cultura dos serviços públicos são reformadas. [...] Ao fazer isso, busca introduzir novas orientações, remodela as relações de poder e afeta como e onde são feitas as opções de políticas sociais" (Clarke; Cochrane; Mclaughlin, 1994, apud BALL, 2005, p.539-564).

O novo gerencialismo representa, assim, a inserção de nova forma de poder no setor público, sendo "instrumento para criar uma cultura empresarial competitiva" (Bernstein, 1996 apud BALL, 2005, p. 544), destruindo os sistemas ético-profissionais que prevaleciam nessas instituições e substituindo-os por sistemas competitivos. Em contraposição ao sistema de controle burocrático, pouco eficiente e repressivo do espírito empreendedor dos servidores, estabelece um modelo de organização centrado nas pessoas, em que o sucesso competitivo pode ser alcançado por meio da restrição dos sistemas de controle, da motivação das pessoas para produzir qualidade e do seu esforço em busca da excelência. Enfatiza, também, a atenção constante visando à qualidade, próxima do consumidor e do valor da inovação. Essas novas estruturas e funções da gestão educacional enfatizam políticas, auditoria, regulação e unidades de prestação de 
serviço separadas, e refletem o papel de controle a distância pelo Estado mínimo, ou aquilo que Neave (1998) chamou de Estado Avaliador.

Na educação superior, esse novo gerencialismo leva as instituições do setor público a se inserirem numa nova cultura de performances e competição, a partir da descentralização e dos incentivos à constituição de um novo perfil institucional. Isso faz com que convivam ao mesmo tempo as velhas formas, centradas no controle direto, mediante a ameaça de punição, e o novo gerencialismo, em que prevalecem processos de autorregulação, no qual as instituições devem assumir performances de qualidade e excelência supostamente livres dos mecanismos anteriores de repressão.

Entre as influências que a economia produziu na mercantilização da educação, Ball inscreve a performatividade, descrita como "uma tecnologia, uma cultura e um modo de regulação que se serve de crítica, comparações e exposições como meio de controle, atrito e mudanças" (2002, p. 4). A medida da produtividade e de exposição pública da qualidade é dada pelos desempenhos dos sujeitos individuais e/ou das organizações. A performatividade muda significados, produz novos perfis e garante o alinhamento com a política do Estado, facilitando o seu papel de monitoramento, e permitindo que ele se insira profundamente nas culturas, práticas e subjetividades das instituições do setor público e de seus trabalhadores, mesmo sem parecer fazê-lo. As instituições corporativas e performativas oferecem novas possibilidades de qualidade e de excelência, ao fornecerem "a cada membro de uma organização a possibilidade de exprimir sua iniciativa individual e desenvolver plenamente seu potencial a serviço da empresa". Isso também os torna suscetíveis de serem substituídos por técnicos do setor público, formados segundo princípios livres dos rigores da reflexão moral (Du Gay, 1996 apud BALL, 2006, p. 15).

Nesse sentido, apresentação, postura, impressões causadas e passadas devem ser cuidadosamente elaboradas e administradas, como parte da aceitação e da substância do desempenho e da qualidade, devendo ser construídas sempre com um olhar na concorrência. A publicação de indicadores de desempenho, a resposta a julgamentos oficiais acerca da qualidade ou a escolha de clientes e consumidores não podem ser confiadas apenas à sorte. Assim, a performatividade não muda apenas a maneira de fazer as coisas, mas, também, a de pensar sobre o que fazer.

Ball (2006) destaca a importância do uso de uma linguagem nova para descrever papéis e relacionamentos. Desse modo, a aprendizagem é reapresentada como o resultado de uma política de custo-benefício, ou melhor, o êxito é resultante de um conjunto de metas de produtividade. Essas performances se fundamentam em práticas de ensino, aprendizagem e de gestão acadêmica, 
reduzidas e subordinadas a partir da utilização de um suporte material prescritivo, estandardizado e, por isso mesmo, passível de ser classificado, mensurado, comparado com a finalidade de se atingirem metas.

O autor considera que há um novo discurso de poder nas sociedades pós-industriais, materializado na responsabilização (accountability) e competição, legitimando novas identidades sociais. Nesse cenário, a educação adquire maior destaque já que, segundo Lopes (2004), busca-se:

A transmissão da cultura da performatividade para a constituição de sujeitos mais produtivos, eficientes, polivalentes, proativos, assertivos, disponíveis à compreensão de outras culturas. Um sujeito onicompetente, pois está em perene prontidão para a demonstração de seus conhecimentos e desempenhos, em constante e permanente processo de avaliação, no qual o funcionamento do poder é garantido pelo controle constante da performatividade (p. 64).

A sobrevivência no mercado educativo passa a ser o propósito comum, em que pragmatismo e autointeresse, e não mais ética e julgamento profissional, são as bases para os novos jogos de linguagem organizacional. Para Ball, citando Willmott, requer-se de "empregados, individual e coletivamente, que simultaneamente reconheçam e se responsabilizem pela relação entre a segurança do seu posto de trabalho e a sua contribuição para a competitividade dos bens e dos serviços que produzem", encorajando-os a ver o próprio desenvolvimento como oriundo e relacionado ao crescimento da instituição (Willmott, 1993, p. 215-252 apud BALL, 2001, p. 522.).

$\mathrm{O}$ ato do ensino e a subjetividade dos/as professores/as alteram-se profundamente no contexto desse novo modelo de gestão da qualidade e da excelência e perante as novas formas de controle empresarial realizadas através de marketing e competição. O desempenho funciona como medida de produtividade, resultado ou exposição de qualidade, significando, resumindo ou representando a qualidade e o valor de um indivíduo ou organização num campo de avaliação.

Ball (2002) afirma que no trabalho do novo gerente está compreendido incutir uma atitude e uma cultura nas quais os docentes se sintam responsáveis e, ao mesmo tempo, investidos da responsabilidade pelo bem-estar da instituição (accountability). Essas novas pedagogias invisíveis de gerencialismo, realizadas por meio de avaliações, análises e formas de pagamento relacionadas ao desempenho, ampliam o que pode ser controlado na esfera administrativa. A prática do ensino é reelaborada e reduzida a seguir regras geradas de modo exógeno e a atingir metas. Isso gera a lógica que permite substituir uma mão-de-obra e culturas institucionais especializadas por culturas e sistemas de gestão genéricos, que visam a obter desempenho, melhoria da qualidade e eficácia. 
Em síntese, a qualidade na educação tem sido referenciada à cultura empresarial competitiva, que utiliza um modelo de gestão capaz de responsabilizar organizações e indivíduos pelo máximo desempenho. Nesse novo modo de gestão privada que se instala nas instituições públicas, a qualidade comumente se faz representar pelo cumprimento de metas de produtividade, desempenho, eficácia, efetividade e excelência através do monitoramento e produção de informações, sendo gerida pelo marketing e pela competição, objetivando o pragmatismo e o desempenho.

\section{NOVA GESTÃO PÚBLICA E A QUALIDADE DA EDUCAÇÃO SUPERIOR}

Ao analisar questões centrais da condição macropolítica econômica global do mundo atual, Dale (2011) sugere formas pelas quais os desafios gerados por essa condição na sociedade se transformam em desafios para a universidade. Aponta que as relações entre qualidade e seus indicadores estão mudando, com trajetórias que começam a divergir, em função de uma ideia particular de modernizar a educação superior que está sendo globalizada por meio dos esforços das organizações internacionais de avaliação (Banco Mundial e OCDE). Ações com base em concepções difusas são promovidas por essas organizações, de forma a serem assumidas pela educação superior como resposta às demandas da economia global.

Nesse contexto, como observam Leite e Genro (2012), existe uma hierarquia entre os atores globais que se envolvem com educação superior. As agências globais de ciência, cultura e educação ocupam o plano superior, seguidas pelas agências do mundo político global e seus parceiros, os quais possuem uma carteira de conhecimentos sobre educação superior e mantêm as iniciativas para seu suporte. Na sequência, estão as agências acreditadoras de agências e outros atores globais, como as agências ou instituições produtoras dos rankings internacionais de prestígio. Num plano inferior dessa hierarquia se encontram agências de acreditação que reúnem outras acreditadoras. E num plano ainda mais abaixo, encontram-se as agências avaliadoras nacionais. As IES, por sua vez, são englobadas (ou fagocitadas, no dizer das autoras), por esta grande e articulada estrutura que engloba também os acadêmicos, técnicos e estudantes. Nesse nível é que se introduzem as avaliações no nível local, levando as IES a procurar uma posição de destaque no mercado nacional ou internacional de educação superior.

Como aponta Guerra (2010), quando uma IES, curso ou sistema de educação superior é acreditado/avaliado, sua qualidade é automaticamente legitimada no âmbito global. Ou seja, o cumprimento das regras ou a contemplação 
de indicadores pré-estabelecidos por aqueles organismos é que define, em linhas gerais, a qualidade de um sistema de educação superior, independente de uma definição do conceito de qualidade.

Esse modelo emergente de universidade global implica um conjunto de características: "missão global, intensidade de pesquisa, novos papéis para os professores, fomento diversificado, recrutamento global, aumento de complexidade, novos relacionamentos com o governo e a indústria, e colaboração global com instituições similares" (Mohrman; M, A; Baker, 2008 apud DALE, 2011, p. 60-61). Segundo Dale, esse modelo tem por consequências a redução da influência dos estados-nação sobre suas universidades; muitas das características do modelo estão enraizadas na experiência americana recente; e a natureza internacional é restrita a um grupo pequeno de instituições que vai representar a inclusão de ponta das forças da globalização pela Educação Superior.

Robertson (2011, p. 433) observa que "a NGP teve um impacto importante na maneira como as universidades realizavam sua missão central de ensino e pesquisa, através da utilização de indicadores e metas, o uso de padrões explícitos e medidas de desempenho, e a parcimônia no uso dos recursos". Ela introduziu, ainda, uma mudança cultural importante, com a emulação de valores e práticas centrais de negócios, na sua forma de ser administrada e na administração de seu pessoal.

Nesse sentido, segundo Dale (2011), o termo qualidade aponta para a emergência das expectativas de universidades enquanto instituições e da educação superior como a setor da economia e a reflete. A qualidade pode ser vista, então, como resultado dos mecanismos que proporcionam a filiação a uma comunidade internacional de educação superior, enquanto os indicadores "estão se transformando na base do estabelecimento de uma pretensão de excelência individual, por meio da comparação competitiva em escala global” (p. 61), modelada por mecanismos de classificação. Ao mesmo tempo em que a gestão da qualidade proporciona elementos de proteção ao consumidor e a outras partes interessadas contra produtos ou serviços inadequados ou fraudados, ela leva à categorização e reificação do conceito de qualidade, sem significado próprio, extraído como foi, de um ambiente particular.

O autor observa que, com a inserção numa comparação competitiva global, o foco está deslocando-se da garantia da qualidade para os indicadores quantificáveis. Isso implica novas formas de gerenciamento de riscos, ou seja, no estabelecimento de um sistema de medidas regulatórias com o objetivo de modelar quem pode correr mais riscos e como (DALE, 2011, p. 63). Ao contrário da confiança, que assume aspectos de incertezas, o gerenciamento de riscos busca dar certo grau de medição para as expectativas, mesmo diante das incertezas. 
Enquanto, numa economia global do conhecimento, a gestão voltada para a qualidade não cria riscos significativos nem possibilita que eles sejam gerenciados, no gerenciamento de riscos, as instituições se tornam atores empreendedores estratégicos, engajados em práticas como competição e desenvolvimento de estratégias antes exclusivas do setor privado. "A reputação emerge como uma moeda central e dominante de risco para as universidades" (DALE, 2011, p. 64), e se constitui em novo tipo de métrica de performance, a grande fonte de risco institucionalizado que incentiva as organizações a apoiar avaliadores legitimados, fornecendo-lhes informações e internalizando, dessa forma, os elementos de medida como variáveis integrantes de sua performance. Em conclusão, Dale afirma que qualidade e indicadores desenvolvem diferentes trajetórias, exercendo a primeira papel mais limitado, embora mais importante, na governança e organização da universidade.

No contexto atual, o autor sugere ser preciso considerar o papel do gerenciamento de risco da reputação no nível da instituição e, também, a necessidade de que os rankings "desencadeassem respostas performativas [o] que sustenta o potencial (ou, claro, a ameaça) mais ampla do uso extensivo dos indicadores que envolvem mais do que assinalar as caixas" com os itens de avaliação. A performatividade é mediada por mecanismos quantitativos usados pelas agências internacionais de avaliação, que "não apenas medem, mas efetivamente definem a natureza das reputações das universidades” (DALE, 2011, p. 74), em razão da capacidade que os rankings têm de não apenas ordenar, mas de determinar a base dessa ordem.

\section{EDUCAÇÃO SUPERIOR BRASILEIRA: O CONCEITO DE QUALIDADE EM DISPUTA PELAS ARENAS DE PODER}

No Brasil, a concepção de qualidade na educação superior está referenciada a uma política pública, por meio da lei n 10.861 de 2004, que criou o Sistema Nacional de Avaliação da Educação Superior (SINAES). Conforme mencionado, a polissemia da qualidade pode ser atribuída à disputa entre as diferentes arenas de poder com interesses na Educação Superior.

Segundo o sistema e-MEC, o Brasil tem 1.603 mantenedoras e 2.638 IES, a maioria vinculada ao sistema federal de ensino, composto por 107 IES federais, mantidas pela União, e por $2.330 \mathrm{IES}$, mantidas pele setor privado $^{2}$. O setor público segmenta-se em três grupos: federal, estadual e municipal ocupando 
este último parcela restrita do conjunto ${ }^{3}$. O setor privado segmenta-se em cinco grupos: (1) comunitários, (2) confessionais, (3) filantrópicos, (4) privados em sentido estrito, de natureza não lucrativa e (5) privados de caráter mercantil. Entre estas últimas, há mantenedoras com capital aberto nas bolsas de valores, além de grandes conglomerados educacionais, que detêm cerca de $40 \%$ das matrículas da rede privada (PELLEGRINI, 2014).

O setor público e o privado se constituem em diferentes arenas políticas, com interesses singulares e disputando concepções diferentes da educação superior, partilhando distintas noções de qualidade. Militam ainda nesse campo outras arenas sem relação direta com a Educação Superior, isto é, são setores da sociedade ou atores políticos que se alinham aos interesses das IES e das mantenedoras, como é o caso dos investidores.

Constitui um equívoco considerar que as IES públicas, sobretudo as federais e estaduais, são um bloco político homogêneo, pois as distinções encontradas nas posições que ocupam nos rankings internacionais podem definir interesses diversos quanto a seu papel nas políticas educacionais e de ciência e tecnologia. Ademais, os interesses de seus diferentes segmentos - reitores, docentes, estudantes e técnicos administrativos - não costumam ser convergentes.

Também no aparato estatal, diferentes setores podem assumir posicionamentos distintos. No caso do Ministério da Educação, órgãos como a Secretaria de Ensino Superior (SESu), Secretaria de Regulação e Supervisão da Educação Superior (SERES), o Instituto Nacional de Estudos e Pesquisas Educacionais Anísio Teixeira (INEP), o Conselho Nacional de Educação (CNE) ou a Comissão Nacional de Avaliação da Educação Superior (CONAES), nem sempre estão alinhados nas percepções sobre seu objeto. Ressalte-se que, atualmente, a SERES atua com elevado grau de autonomia e como órgão de regulação, sendo que suas decisões sequer estão sujeitas à homologação ministerial, critério este que não é dispensado para os pareceres do $\mathrm{CNE}$, a despeito de demanda desse colegiado. Énfase maior nessa característica pode vir a ser alcançada, caso seja aprovado no Congresso Nacional o Projeto de Lei no 4.372 de 2012, para criar o Instituto Nacional de Supervisão e Avaliação da Educação Superior (INSAES), a configurar o que Nunes, Fernandes e Vogel (2012) denominam agência reguladora atípica.

Essa diversidade dá uma noção da teia de interesses e diferentes percepções em torno da Educação Superior e da concepção de qualidade, configurando-se como diferentes arenas políticas Lowi (2009) categoriza as políticas e as arenas em três tipos: regulatória, distributiva e redistributiva, que se distinguem quanto

3 De acordo com a organização federativa brasileira, a participação do segmento estadual e municipal no Sinaes não é obrigatória, tendo se restringido ao ENADE.

728 - RBPAE - v. 32, n. 3, p. 719 - 737 set./dez. 2016 
aos benefícios ou coerções, tipos de demanda e relações que estabelecem para as partes interessadas. Pela afinidade que apresentam com o modelo do SINAES, vamos deter-nos nas políticas e nas arenas regulatórias e burocráticas. Segundo o autor, arenas regulatórias são constituídas de políticas que

\footnotetext{
trabalham diretamente com a conduta individual, onde as identidades e as questões de conformidade e não conformidade devem estar envolvidas [...] impõem obrigações e sanções. [...] Se efetivamente implementadas, elas podem criar um ambiente de conduta favorável ou não favorável á sua execução. Isso, no entanto, é uma hipótese comportamental sobre o impacto político ou social e não tem nada a ver com a definição da própria norma. (p. 148).
}

Política, segundo Lowi (2009), é uma "regra formulada por alguma autoridade [...] expressando a intenção de influenciar o comportamento dos cidadãos, individual ou colectivamente, pelo uso de sanções positivas e negativas" (p. 21). Acrescente-se a essa formulação a feita por Deutsch (1983), de que a "política é o controle mais ou menos imperfeito do comportamento humano, controle que resulta em hábitos voluntários de aquiescência, combinados com a ameaça de uma coerção provável” (p. 4). Já para Bowe, Ball e Gold (1992), a política se desdobra em política proposta, política de fato e política em uso, mas nem sempre os atores atuam nas três fases. É mais comum a atuação no momento da política em uso, em que o poder de influência é exercido sobre a arena burocrática, para regulamentar e executar a política.

Lowi (2009) considera que não apenas os policy makers representam determinadas arenas. Também o corpo funcional dos órgãos públicos se enquadra como arena burocrática, capaz de alterar os rumos da política de fato, no momento de sua implementação, isto é, da política em uso. Para esse autor, a arena burocrática se restringe à alta burocracia estatal.

Além dos reguladores, que atuam na execução, supervisão e regulamentação da política, cabe considerar outros níveis da burocracia envolvidos com a implementação da política, os "burocratas no nível da rua” (Lipsky, 1980 apud OLIVEIRA, 2014, p. 65). São os servidores das escolas públicas, hospitais etc, tais como professores, médicos e técnicos, constituindo-se as unidades de gestão onde atuam esses servidores em arenas políticas. Para Oliveira, as burocracias públicas e privadas são estruturas conflituosas, não são neutras nem operam em simbiose, e os burocratas "tampouco estão comprometidos única e exclusivamente com os objetivos das instituições nas quais estão inseridos" (Idem, p. 51). Ressalte-se que, embora também possam modificar a política em uso, os burocratas no nível da rua constituem instância distinta da arena burocrática de que trata Lowi. 
Oszlak (1982) sustenta que a burocracia estatal é definida como uma cadeia lógica e sequencial de comportamentos que conduziria a resultados previstos, mas, "o processo de materialização da política afeta aos atores da sociedade civil cujo comportamento condiciona [...] a natureza e oalcance da ação nos diferentes níveis de implementação" (p. 28). A burocracia é afetada tanto de cima para baixo (autoridades e políticos) quanto de baixo para cima (sociedade). Para entender o percurso da política, diz ele, não interessa só o encadeamento das ações intraburocráticas que mudam a política em ação, mas também a dinâmica social gerada por este processo e seus efeitos sobre o comportamento dos agentes estatais. Para o autor, a trajetória da burocracia é mais bem descrita como sendo errática, sinuosa e contraditória, e o que nela é feito não deve ser visto "como a tradução, em ação [...] de um conjunto de normas [...] ref1ete melhor o propósito de compatibilizar os interesses de suas clientelas e os seus próprios, com aqueles sustentados em seus projetos políticos" (Oszlak (1982, p. 28).

$\mathrm{Na}$ Constituição Federal brasileira de 1988, os termos avaliação e qualidade ocorrem, respectivamente, oito e dezesseis vezes, associados à função fiscal, regulatória ou gerencial do Estado. Para Ristoff e Dias Sobrinho e (2002), a avaliação se tornou um compromisso público e nessa condição um conjunto robusto de políticas públicas foram desenvolvidas. Em 2001, com a aprovação do Plano Nacional e Educação (PNE), vigência 2001-2010, foi atribuída à União a tarefa de criar um sistema de avaliação com vistas à melhoria da qualidade da educação superior (BRASIL, 2001).

Em decorrência da proposição de que os resultados das avaliações de qualidade deveriam orientar a expansão da Educação Superior, em abril de 2003, a Sesu convocou uma Comissão Especial de Avaliação (CEA) para oferecer as bases epistemológicas do sistema de avaliação, dali resultando a proposta do SINAES. A composição da CEA não foi homogênea, pois entre os quinze membros vinculados à academia, dois eram provenientes do segmento privado, não lucrativo, onze das IFES, um do segmento estadual e um do segmento municipal (BRASIL/MEC, 2003a; 2003b). Integraram ainda a comissão, dois membros vinculados ao MEC, um à Capes e dois ao INEP. Excluídas da participação nessa etapa, embora uma grande diversidade de entidades públicas e privadas tenham se manifestado nas diversas audiências públicas, não restam dúvidas de que as demais arenas iriam buscar formas de interferir a posteriori nessa política.

Deve ser observado que tanto o SINAES quanto a concepção de qualidade atrelada à accountability e à regulação da Educação Superior são práticas relativamente recentes, embora a segunda esteja presente há mais tempo na gestão de empresas. Por isso, não se pode atribuir apenas aos resultados das avaliações do SINAES a acelerada expansão verificada no setor privado mercantil. Não seria 
apenas a qualidade das suas atividades que motivaram sua expansão, mas talvez os recursos de poder da arena na qual se situam seus mantenedores.

No momento atual, convivem no âmbito do SINAES cinco métricas de qualidade: avaliação institucional (AVALIES), avaliação de cursos (ACG), Exame Nacional de Desempenho dos Estudantes (ENADE), Conceito Preliminar de Cursos (CPC) e Índice Geral de Cursos (IGC), sendo que as três últimas convergem em seus resultados, mas pouco se comunicam com as duas primeiras. E apenas essas três têm seus resultados divulgados anualmente: o ENADE, desde 2004, enquanto o CPC e o IGC desde 2007.

Para conhecer os resultados da AVALIES e da ACG é preciso buscar pelos repositórios oficiais, como o sistema e-MEC, o Diário Oficial da União (DOU), ou o site do Conselho Nacional de Educação (CNE). Levantamento feito em 2015 sobre os processos regulatórios constantes do sistema e-MEC ${ }^{4}$ e no DOU ${ }^{5}$, informa que das 1.876 IES existentes em 2004, segundo o Censo da Educação Superior que protocolaram o pedido de recredenciamento entre 2007 e $2009^{6}$, apenas 765 (40,8\%) tiveram os processos concluídos pelo CNE (FERNANDES, 2015). Parte desta morosidade é atribuída pela SERES à escassez de servidores, o que justificaria a criação do Insaes, conforme exposição de motivos que acompanhou o PL n 4.372/2012 (BRASIL, 2012). Para esse autor, a opção de regular pelo IGC tem tido como resultado a paralização, desde 2007, de processos de recredenciamento cuja análise foi concluída pela SERES, e não são submetidos ao CNE para serem finalizados de acordo com o que determina a legislação.

Aliados ao ENADE, o CPC e o IGC passaram a ter protagonismo na regulação e na orientação de um conjunto de políticas (GRIBOSKI, 2015, p. 169), expressando a alteração na interpretação das bases epistemológicas dessa política pública de avaliação pelos reguladores. Ilustram, ainda, a intervenção promovida pela arena burocrática na política, na qual o processo de gestação desses índices pela SESu, de 2007 a 2008, revela a presença de uma postura algo errática e sinuosa na condução da política, ao mesmo tempo em que contraditória ao que postulava a CEA/2003 e ao que postula a lei do SINAES.

Essa mudança de rumo, que passou a privilegiar a dispensa de visitas de comissões de avaliação, imprimiu um caráter assistêmico ao SINAES, pois os reguladores passaram a focalizar os resultados de apenas uma de suas métricas

\footnotetext{
4 Levantamento feito em novembro de 2015.

5 Pesquisa na seção I do diário, correspondente ao período de abril de 2004 a agosto de 2015.

6 Após uma tentativa frustrada em 2005, o MEC editou a Portaria Normativa $n^{\circ} 1$ de 2007, definindo o calendário de 2007 a 2009 para que as IES protocolassem seus processos de recredenciamento institucional e de renovação de todos os seus cursos de graduação. (BRASIL, 2007).
} 
de avaliação, o ENADE, dispensando a maior parte das avaliações presenciais de cursos e dilatando os prazos para a análise dos recredenciamentos das IES. Nesse último caso, a existência de cerca de $70 \%$ de processos ainda em tramitação, alguns desde 2007, como informa Fernandes (2015), impede uma avaliação global dos objetivos da lei e a conclusão de um ciclo que compreenda todas as avaliações.

\section{CONSIDERAÇÕES FINAIS}

Neste texto, vimos que a disputa pelo conceito de qualidade aporta benefícios à avaliação e potencializa o jogo de interesses na Educação Superior, ao mesmo tempo em que revela sua polissemia e destaca a perspectiva regulatória no sistema educacional brasileiro. Esse efeito foi analisado por Neave (2014), para quem Estado Avaliador e Estado Regulador são duas faces da mesma moeda.

Mais que identificar as múltiplas concepções defendidas pelas diferentes arenas em disputa, o artigo explicita que a qualidade na performatividade do gerencialismo da Educação Superior brasileira se configura como um conceito abrangente em permanente mutação. A revisão permanente de suas regulamentações é o reflexo da pressão exercida pelas forças presentes nas diferentes arenas.

Em que pesem as disputas em torno da qualidade que ocorre entre as diversas arenas, a avaliação de qualidade, além de ser uma conquista da sociedade brasileira, é preceito constitucional e tem lei própria. Algumas expectativas geradas com a lei não se confirmaram como, por exemplo, a de produzir emancipação e maior grau de autonomia das IES ou a melhoria da qualidade. Nesse sentido, é preciso considerar, até que ponto o papel desempenhado pelo conceito de qualidade no novo gerencialismo se articula com os princípios geradores do SINAES, tal como formulados pela CEA em 2004.

Para justificar sua afinidade com o gerencialismo, o SINAES poderia ser mais eficaz, oferecendo à sociedade medidas precisas sobre a melhoria do sistema e a emancipação prometida. A despeito disso, poderia ser esperada também maior transparência, para que a sociedade pudesse compreender situações como aquela em que se encontram 207 IES privadas: 63 foram descredenciadas por medida de supervisão, sendo duas universidades, um centro universitário e 60 faculdades; 72, 70 faculdades e dois centros universitários que estão "em descredenciamento voluntário" e outras 72 efetivamente descredenciadas, sendo 70 faculdades e duas universidades, conforme registra o sistema e-MEC ${ }^{7}$, a maioria delas em razão dos resultados obtidos no ENADE e IGC. Ainda por essa razão, na mesma

7 A consulta ao sistema e-MEC, perfil das IES, foi feita em 03 set. 2016. http://emec.mec.gov.br/ Módulo "consulta avançada".

732 - RBPAE - v. 32, n. 3, p. 719 - 737 set./dez. 2016 
fonte precisariam ser mais bem compreendidas 39 IES que tiveram suspensão do contrato FIES, 40 do PRONATEC, 40 do PROUNI, e dois centros universitários que tiveram suspensas as prerrogativas de autonomia. Essas informações não têm divulgação ampla, só podendo ser obtida em pesquisa no sistema e-MEC.

Da mesma forma, seria desejável a divulgação das razões pelas quais não foi dado seguimento aos recredenciamentos de todas as IES, de modo a cumprir o cronograma estipulado pela Portaria Normativa $n^{\circ} 1 / 2007$, bem como das razões pelas quais avaliações presenciais dos cursos de graduação foram substituídas por índices transitórios, desvirtuando o que foi previsto em lei. A garantia de qualidade exige, também, dos gestores do SINAES, para usar expressão cunhada por Afonso (2015, p. 1318), deixar de oferecer à sociedade uma "transparência opaca" e seletiva de seus resultados.

\section{REFERÊNCIAS}

AFONSO, Almerindo Janela. Recuo ao cientificismo, paradoxos da transparência e corrupção em educação. Educação e Pesquisa, São Paulo, v. 41, n. especial, p. 1313-1326, dez. 2015..

BALL, Stephen. Sociologia das políticas educacionais e pesquisa crítico-social: uma revisão pessoal das políticas educacionais e da pesquisa em políticas educacionais. Currículo sem Fronteiras, v.6, n.2, p.10-32, jul./dez. 2006.

- Profissionalismo, gerencialismo e performatividade. Cadernos de Pesquisa, v.35, n.126, p.539-564, set./dez. 2005.

- Performatividade, privatização e o pós-Estado do Bem-Estar. Educação e Sociedade, Campinas, v.25, n.89, p.1105-1126, set./dez. 2004.

. Reformar escolas/reformar professores e os terrores da performatividade.

Revista Portuguesa de Educação, Universidade do Minho/PT, v.15, n.2, p.0323, 2002.

- Diretrizes políticas globais e relações políticas locais em educação. Currículo sem Fronteiras, v.1, n.2, p.99-116, dez. 2001.

BOWE, Richard; BALL, Stephen; GOLD, Anne. Reforming education \& changing schools: case studies in policy sociology. London: Routledge, 1992. 
BRASIL. Câmara dos Deputados. Projeto de lei n 4.372, de 31 de agosto de 2012. Cria o Instituto Nacional de Supervisão e Avaliação da Educação Superior - INSAES, e dá outras providências. Disponível em:<http://www.camara.gov. $\mathrm{br} /$ proposicoesWeb/fichadetramitacao?idProposicao=554202>. Acesso em: 21 mar. 2016.

Portaria Normativa $n^{\circ} 1$, de 10 de janeiro 2007. Estabelece o calendário de avaliações do Ciclo Avaliativo do Sistema Nacional de Avaliação da Educação Superior - SINAES para o triênio 2007/2009. Diário Oficial [da] República Federativa do Brasil. Brasília, DF, de 11 jan. 2007, seção I, página 07.

.Ministério da Educação. Portaria SESu n. ${ }^{\circ}$ 11, de 28 de abril de 2003. Institui a Comissão Especial de Avaliação e designa seus membros. Diário Oficial [da] República Federativa do Brasil. Brasília, DF,n. ${ }^{\circ}$ 82, de 30 abr. 2003a, Seção 2, página 19.

Portaria Sesu n. ${ }^{\circ}$ 19, de 17 de maio de 2003. Designa membros para a Comissão Especial de Avaliação. 2003b. Diário Oficial [da] República Federativa do Brasil. Brasília, DF n. ${ }^{\circ}$ 101, de 28 mai. 2003b, Seção 2, página 11.

Lei $n^{\circ}$ 10.172, de 9 de janeiro de 2001. Aprova o Plano Nacional de Educação e dá outras providências. Diário Oficial [da] República Federativa do Brasil. Brasília, DF, n. 7, 10 jan. 2001, Seção 1, p. 177, 2001.

- Constituição da República Federativa do Brasil. Diário Oficial da União, Brasília, 5 out. 1988, Seção I, p. 1.

DALE, Roger. Constructing risk management of higher education sector through reputational risk management of institutions. In: MOROSINI, Marília Costa (Org.). Qualidade da educação superior: reflexões e práticas investigativas. Porto Alegre: EDIPUCRS, 2011. p. 32-53 e 54-76. Disponível em:<http://www. pucrs.br/edipucrs $>$.Acesso em: 01 fev. 2016.

DEUTSCH, Karl Wolfgang. Política e governo. 2.ed. Tradução Maria José da Costa Félix Matoso Miranda Mendes. Brasília: Editora Universidade de Brasília, 1983. 
FERNANDES, Ivanildo. Quantificando a ineficiência do Sistema e-MEC. Documento de Trabalho $\mathrm{n}^{\circ}$ 108. Rio de Janeiro: Observatório Universitário, 2015. Disponível em:<http://www.observatoriouniversitario.org.br>. Acesso em: 19 mar. 2016

GRIBOSKI, Cláudia. Regular e/ou induzir qualidade? Os cursos de pedagogia nos ciclos avaliativos do Sinaes. Brasília, 2015. 481 p. Tese (Doutorado em Educação) - Universidade de Brasília. Brasília, 2015.

GUERRA, Margareth. Redes de Avaliação e Acreditação Latino-Americanas: RANA - MERCOSUR EDUCATIVO. In: LEITE, Denise (Org.).Inovação, avaliação e tecnologias da informação. Porto Alegre: Pacartes, 2010. p. 53-72.

LEITE, Denise; GENRO, Maria Elly H. Avaliação e internacionalização da educação superior: Quo vadis América Latina?Avaliação, Campinas, v. 17, n. 3, nov. 2012. Disponível em: <http://www.scielo.br/scielo.php?pid=S141440772012000300009\&script=sci_arttext>. Acesso em: 14 de maio de 2013.

LOPES, Alice Casimiro. Políticas de currículo: mediação por grupos disciplinares de Ciência e Matemática. In: LOPES, Alice Casimiro; MACEDO, Elisabeth. Currículo de Ciência em Debate.Campinas: Papirus, 2004. p. 45-76.

LOWI, Theodor. Arenas of power. USA: Paradigm publishers, 2009.

MOHRMAN, Kathryn; MA, Wanhua; BAKER, David. The research university in transition: the emerging global model,Higher Education Policy,v.21, p. 5-27, 2008.apudDALE, Roger. Constructing risk management of higher education sector through reputational risk management of institutions. In: MOROSINI, Marília Costa (Org.).Qualidade da educação superior: reflexões e práticas investigativas. Porto Alegre: EDIPUCRS, 2011. p.32-53e 54-76. Disponível em:<http://www.pucrs.br/edipucrs>.Acesso em: 01 fev. 2016.

NEAVE, Guy. A few impertinent questions to those who are engaged in selling the family silver: prospects for the evaluative state. CIPES. 2014. Disponível em: $<$ http://sigarra.up.pt/up/en/noticias_geral.noticias_cont?p_ id=F638094035/GuyNeave.pdf $>$ Acesso em: 01 fev. 2016.

The evaluative state reconsidered. European Journal of

Education, Oxford, 1998, vol. 33, nº 3, p. 265-284. 
NEWMAN, Janet; CLARKE, John. Gerencialismo. Educação e Realidade, Porto Alegre, v. 37, n. 2, p. 353-381, maio/ago. 2012.

NUNES, Edson de Oliveira; FERNANDES, Ivanildo; VOGEL, Julia. O INSAES como agência reguladora atípica (análise a partir do PL $\mathrm{n}^{\circ}$ 4372/2012). Observatório Universitário, Documento de Trabalho no 104, out. 2012, 35 p. Disponível em http://www.observatoriouniversitario.org.br/documentos_de_ trabalho/documentos_de_trabalho_104.pdf. Acesso 10 de março de 2016.

OLIVEIRA, Breynner Ricardo de. A implementação do Programa Bolsa Família sob a perspectiva da condicionalidade educacional: uma análise a partir dos agentes públicos de base. Belo Horizonte, 339 p. Tese (Doutorado) - Faculdade de Educação,Universidade Federal de Minas Gerais, 2014.

OSZLAK, Oscar. Políticas públicas e regimes políticos: reflexões a partir de algumas experiências latino-americanas. RAP, Rio de Janeiro, v. 16, n. 1, 1982. Disponível em:<http://bibliotecadigital.fgv.br/ojs/index.php/rap/article/ view/11455>. Acesso em: 07 abr. 2016.

PELLEGRINI, Marcelo. Ensino superior: Prouni criou milionários em troca de má qualidade na educação. Entrevista com Wilson Mesquita de Almeida. Carta Capital. On line. São Paulo, 19 dez. 2014. Disponível em:< http:// www. cartacapital.com.br/educacao/prouni-criou-milionarios-em-troca-de-maqualidade-na-educacao-7396.html>. Acesso em: 23 mar. 2016.

RISTOFF, Dilvo Ivo; DIAS SOBRINHO, José. Avaliação democrática: para uma universidade cidadã. Florianópolis: Insular, 2002.

ROBERTSON, Susan. Desafios enfrentados por universidades em um mundo em globalização. In: Qualidade na educação superior: reflexões e práticas investigativas. Porto Alegre: EDIPUCRS, 2011. p. 430-451. Disponível em: <http://www.pucrs.br/edipucrs>.Acesso em: 01 fev. 2016.

WILLMOTT, Hugh. Strength is Ignorance; Slavery is freedom: Managing Culture in Modern Organizations. Journal of Management Studies, 30(4), 215-252. 1993. apudBALL, Stephen. Diretrizes políticas globais e relações políticas locais em educação. Currículo sem Fronteiras, v.1, n.2, p.99-116, dez. 2001. 
MARIA DO CARMO LACERDA PEIXOTO tem graduação em Sociologia pela UFMG e é Doutora em Educação pela UFRJ. Professora titular da Faculdade de Educação da Universidade Federal de Minas Gerais - UFMG é pesquisadora da área de políticas para educação superior, tendo diversas publicações sobre a temática. Implantou e dirigiu a Diretoria de Avaliação Institucional da UFMG, e foi presidente da sua Comissão Própria de Avaliação. É pesquisadora da área das políticas para a educação superior, tendo diversas publicações nesta temática, entre livros, coletâneas e artigos. Participa da Rede Universitas/Br, como pesquisadora do Observatório da Educação "Políticas de Expansão da Educação Superior no Brasil”. E-mail: mcarmolp@gmail.com

MARIA DAS GRAÇAS MEDEIROS TAVARES é graduada em Licenciatura em Pedagogia pela Universidade Federal de Alagoas, Mestre em Administração de Sistemas Educacionais pelo Instituto de Estudos Avançados em Educação IESAE/FGV e Doutora em Educação Brasileira pela Universidade Federal do Rio de Janeiro. É professora titular do Departamento de Fundamentos da Educação - TFE da Universidade Federal do Estado do Rio de Janeiro e pesquisadora da área de políticas para educação superior, com diversas publicações sobre as temáticas: educação superior, gestão democrática, extensão universitária e avaliação educacional. Participa da Rede Universitas/Br, como pesquisadora do Observatório da Educação "Políticas de Expansão da Educação Superior no Brasil”. E-mail: graccatavares@uol.com.br

IVANILDO RAMOS FERNANDES é mestrando em Educação pela Universidade de Brasília - UnB, Especialista em Políticas Públicas e Avaliação da Educação Superior pela Universidade Federal da Integração Latino Americana -UNILA/ PR, Bacharel em Direito pela Universidade Candido Mendes- UCAM/RR, onde atua como docente-pesquisador e diretor de regulação, nos temas regulação e avaliação da educação superior. Associado à Rede Universitas/Br, desde 2009, e ao Grupo de pesquisa “Observatório e Pesquisa das Políticas de Avaliação da Educação Superior (POW1). Sua produção científica compreende capítulos de livros, artigos etc. E-mail: iramos@candidomendes.edu.br

FABIANE ROBL é graduada em Bacharelado e Licenciatura em Ciências Biológicas pela Fundação Universidade Regional de Blumenau, Mestre em Educação pela Fundação Universidade Regional de Blumenau e Doutora em Educação pela Universidade de São Paulo. Foi assessora técnica da Comissão Nacional de Avaliação da Educação Superior (CONAES), e consultora no Ministério da Educação, atuando no Plano de Desenvolvimento da Educação PDE. Tem experiência na área de Educação, com ênfase em Educação Superior, atuando principalmente nos seguintes temas: produção acadêmica, grupos de pesquisa, rede de conhecimento, avaliação e políticas públicas da educação superior. Participa da Rede Universitas/Br, como pesquisadora do Observatório da Educação "Políticas de Expansão da Educação Superior no Brasil". E-mail: fabiane.robl@gmail.com 